\title{
KOMPIUTERINĖS TOMOGRAFIJOS ATLIKIMO TAKTIKA IR REIKŠME் VERTINANT GALVOS SMEGENŲ TRAUMĄ BEI PROGNOZE
}

\author{
Alina Vilke் $\dot{e}^{2,3}$, Kristina Pundinaite் ${ }^{1,2}$, Evaldas Keleras ${ }^{1}$, Algirdas Basevičius ${ }^{1}$, \\ Saulius Lukoševičius ${ }^{1}$, Diana Bilskien $\dot{e}^{2}$, Andrius Macas ${ }^{2}$ \\ ${ }^{1}$ Lietuvos sveikatos moksly universiteto Medicinos akademijos Radiologijos klinika, \\ ${ }^{2}$ Lietuvos sveikatos mokslu universiteto Medicinos akademijos Anesteziologijos klinika, \\ ${ }^{3}$ Lietuvos sveikatos moksly universiteto Medicinos akademijos Neuromokslu institutas
}

Raktažodžiai: kompiuterinè tomografija (KT), KT atlikimo taktika, galvos smegenų trauma, KT vertė po galvos smegenų traumos.

\begin{abstract}
Santrauka
Galvos smegenų trauma (GST) visame pasaulyje yra aktuali medicininè bei socialinè problema. Lietuvoje tai yra viena dažniausių invalidizacijos priežasčių. GST apibūdinama kaip būklè, kuriai būdingas kinetinès energijos poveikis kaukolei ir galvos smegenims, sukeliantis funkcinius ir morfologinius smegenų pokyčius bei sutrikdantis jų veiklą. Šiuo metu pradinis ivvertinimas pacientams, patyrusiems galvos smegenų traumas, yra pagrịstas klinikiniais tyrimais pagal Glasgow komos skalę (GKS) ir galvos smegenų kompiuterine tomografija (GSKT). Dažniausiai terapiniai sprendimai yra pagrindžiami šiais tyrimais. Tačiau neretai patiriamos lengvos galvos smegenų traumos, kurių požymius galima matyti tik kompiuterinès tomografijos pagalba, o GKS neatspindi esamo pažeidimo.
\end{abstract}

\section{Ivadas}

Galvos smegenų trauma (GST) yra viena dažniausių mirties priežasčiu ir bendro mirtingumo struktūroje užima trečiają vietą po širdies ir kraujagyslių bei onkologinių ligų. S. T. Dawodo teigimu, ligoninèse nuo galvos smegenu traumų miršta 6/100 tūkstančių, o nepasiekę stacionaro 17/100 tūkstančių gyventojų. Lengva galvos smegenų trauma nustatoma 131 iš 100 tūkstančių, vidutinio sunkumo 15 iš 100 tūkstančių, sunki - 14 iš 100 tūkstančių. Daugiausia asmenų iki 40 metų amžiaus miršta dẻl ịvairių išorinių priežasčių, tarp jų ir traumų. Mirtys dèl galvos smegenų traumų sudaro apie 30 proc. visų trauminių mirčių [17].

GST yra vienas dažniausių neurologinių sutrikimų.
Iš visų GST 90 proc. yra lengvos, jų dažnis siekia 100300/100 tūkstančių kasmet. Intrakranijinès lengvos galvos smegenų traumos (LGST) komplikacijos nėra dažnos (10 proc.). Tokių traumų komplikacijų gydymui labai retai prireikia neurochirurginès intervencijos (1 proc.), tačiau kartais jos gali būti pavojingos gyvybei (mirtingumas - 0,1 proc.) [20]. Sunkių galvos smegenų traumų (SGST) baigtys dažnai yra nepalankios, neretai baigiasi mirtimi, dalis ligonių tampa neịgalūs, nemaža dalis jų lieka nuolatinès vegetacinès būklès. Ligonių po sunkių ir vidutinio sunkumo trauminių galvos smegenų sužalojimų gydymas ir reabilitacija kelia daug problemų, tačiau laiku ir tinkamai suteikta pagalba sumažina mirčių po trauminių galvos smegenų sužalojimų skaičių ir pagerina gydymo rezultatus bei tolimesnes baigtis $[14,6,17]$.

Pirmasis ir svarbiausias tyrimas pacientams, patyrusiems galvos smegenų traumą, yra kompiuterinè tomografija. GST baigtys dažniausiai priklauso nuo radinių galvos smegenų kompiuterineje tomografijoje. Trauminiai rezultatai gali svyruoti nuo izoliuoto linijinio kaukolès lūžio, kuris, kaip paprastai manoma, yra kliniškai nereikšmingas ir su palankiu funkciniu rezultatu, iki ūminès intraaksialinès hematomos (kraujosruvą neurochirurgijoje yra ịprasta vadinti lotynišku terminu - ,hematoma“ ir dèl šios priežasties toliau straipsnyje bus vartojamas šis terminas), kurios gydymui bus reikalingas neurochirurginis įsikišimas, taip pat blogesni funkciniai rezultatai ir padidejusi potrauminių komplikacijų galimybė $[14,16,17,19]$.

Straipsnio tikslas - aptarti GST nustatymo galimybes, išanalizuoti galvos smegenų kompiuterinès tomografijos atlikimo taktiką, itaką tolesniems veiksmams bei šio tyrimo vertę artimosioms ir tolimosioms baigtims po GST. Tai padetų pasiekti geresnius rezultatus diagnozuojant bei gydant GST, gerinant jų baigtis. 


\section{Tyrimo objektas ir atlikimo tvarka}

Apžvelgtos Cochrane Library Oxford University Press: Oxford journals, EBSCO Publishing Sci Verse (Science Direct), Emerald Managemente Journals Collection, Medline, Cohrane, Lippincott Williams \& Wilkins duomenu bazès ir jose esantys straipsniai apie galvos smegenu traumų vertinimą, tyrimus, jų baigtis bei GSKT ịtaką GST baigtims. Tačiau literatūroje labai skurdžiai aprašoma ir analizuojama GSKT įtaka pacientams, patyrusiems GST. Baigtys klinikinejje praktikoje dažniausiai vertinamos pagal GOS (Glasgow baigčiu skalę) [15]. Todèl reikètų įvertinti KT atlikimo taktiką ir naudą esant GST.

Kompiuteriné tomografija (KT) - vienas iš informatyviausių radiologinių tyrimų skubiai vertinant galvos smegenų traumas.

\section{GST:}

Indikacijos galvos smegenų KT tyrimui atlikti po

- buvęs ar esamas sąmonès sutrikimas;

- kaukolès lūžimas kraniogramose ar klinikiniai pamato lūžio požymiai (likvorèja ir/ar kraujavimas iš nosies ar ausies);

- esantys ar praeinantys neurologiniai simptomai;

- traukuliai;

- vémimas daugiau negu 1 kartą;

- išliekantis galvos skausmas $[9,10,16,21]$.

KT atlikimo terminai (1 lentelè):

KT atliekama nedelsiant, kai:

- GKS mažiau nei 13 balų tuojau po traumos;

- GKS mažiau nei 15 balų po 2 ir daugiau valandų po traumos;

- įtariamas impresinis ar atvirasis kaukolès lūžis;

- yra kaukolès pamato lūžimo požymių;

- po traumos atsirado traukulių;

- yra židininių neurologinių simptomų;

- vèmé daugiau negu 1 kartą;

- buvęs sąmonès netekimas esant koaguliopatijai.

KT atliekama per 8 val., kai yra:

- mažiau nei 30 min. retrogradiné amnezija;

- bet kokios trukmès amnezija ar sąmonès sutrikimas, jeigu pacientas yra vyresnis negu $65 \mathrm{~m}$.;

- koaguliopatija ar vartojami vitamino K antagonistai;

- pavojingos traumos mechanizmas:

- iškritęs iš automobilio;

- patyręs autoavariją važiuojant didesniu negu 90 km/ val. greičiu;

- partrenktas automobilio ar motociklo;

- kritęs nuo arklio ar dviračio;

- kritęs galva žemyn iš daugiau negu 1 metro aukščio;

- kritęs ant viršugalvio (pvz., nerdamas ị vandenį).

Pakartotinė (kontrolinè) KT atliekama nedelsiant, kai:

- būklè pablogèja 2 ar daugiau GKS balų;
- išryškëja parezès;

- išryškejja anizokorija;

- atsiranda traukulių;

- padidejęs veninis kraujo spaudimas daugiau 20 $\mathrm{mmHg}$ laikosi ilgiau nei $30 \mathrm{~min}$.

Pakartotinè (kontrolinė) KT atliekama vèliau, kai:

- sunki galvos smegenų trauma ir stabili ligonio būklè - rekomenduojama po 6 ir 24 valandu ir po 3 - 5 ir $10-14$ paru arba pagal reikala $[2,8,9,10,16,20,21]$.

Remiantis Europos neurologų asociacijos gairèmis yra sudaromi didieji ir mažieji skubios galvos smegenu KT indikacijos rizikos veiksniai.

Didieji skubios galvos smegenų KT indikacijos rizikos veiksniai:

- pavojingas traumos mechanizmas,

- GKS mažiau negu 15 balų,

- GKS vertès sumažejimas 2 balais,

- klinikiniai kaukolès (pamato) lūžio požymiai,

- vėmimas,

- gydymas antikoaguliantais,

1 lentelè. Galvos smegenų traumų klasifikacija ir skubios galvos smegenų KT indikacijos

\begin{tabular}{|c|c|c|}
\hline Klasifikacija & Charakteristika & $\begin{array}{l}\text { Indikacijos } \\
\text { skubiai } \\
\text { galvos } \\
\text { smegenų } \\
\text { KT }\end{array}$ \\
\hline Lengva & $\begin{array}{l}\text { Apžiūra ligoninèje } \\
\text { GKS = 13-15 } \\
\text { Sąmonès netekimas (jei yra) } \\
30 \text { min. ar trumpesnis }\end{array}$ & \\
\hline \multicolumn{3}{|c|}{ Lengvos smegenų traumos kategorijos } \\
\hline 1 & $\begin{array}{l}\text { GKS }=15 \\
\text { Nėra rizikos veiksnių ar } \\
\text { tik vienas mažas rizikos } \\
\text { veiksnys. } \\
\text { Galvos sužalojimas, nėra } \\
\text { trauminio galvos smegenų } \\
\text { sužalojimo }\end{array}$ & $\mathrm{Ne}$ \\
\hline 2 & $\begin{array}{l}\text { GKS }=15 \\
\text { Su rizikos veiksniais }>1 \\
\text { didysis rizikos veiksnys arba } \\
>2 \text { mažieji. }\end{array}$ & Taip \\
\hline 3 & GKS $=13-14$ & Taip \\
\hline Vidutinè & GKS $=9-12$ & Taip \\
\hline Sunki & GKS $<9$ & Taip \\
\hline Kritinè & $\begin{array}{l}\text { GKS }=3-4, \text { nėra } \\
\text { vyzdžių reakcijos ir nėra } \\
\text { necerebrinès motorinės } \\
\text { reakcijos }\end{array}$ & Taip \\
\hline
\end{tabular}


- potrauminiai traukuliai.

Mažieji skubios galvos smegenų KT indikacijos rizikos veiksniai:

- amžius,

- sąmonès netekimas,

- išliekanti anterogradinè amnezija,

- židininiai simptomai,

- galvos sumušimas,

- GKS balų mažèjimas.

Potrauminių pokyčių KT vertinimas

KT vertinimui standartizuoti rekomenduojama bazalinius pjūvius (nuo foramen Magnus iki turkiabalnio) atlikti 2,5 - 5 mm intervalais, o aukštesnius pjūvius (virš turkiabalnio) iki $6 \mathrm{~mm}$ intervalais, pjūviai turi būti lygiagretūs su akiduobès linija $[6,8]$.

\section{KT tyrimo metu vertinama:}

\section{Hematomos:}

- epidurinès hematomos - dažniausiai lokalizuota konveksitaliai ir sukelta arterinio kraujavimo,

- subdurinès hematomos - taip pat dažniausiai lokalizuotos konveksitaliai ir dažniau sukelta veninio kraujavimo.

Iš pradžių hematomos KT būna hiperdensinès (ūminès), o vèliau pereina ì izodensines ir hipodensines (poūmes, lètines),

- subarachnoidinès kraujosruvos (jeigu įtariama netrauminé jos kilmé, atliekama angiografija jos priežasčiai nustatyti),

- intracerebrinės kraujosruvos dažniausiai prasideda nuo žievès kontūzinių židinių (jeigu ịtariama displastinė jos kilmé, atliekama angiografija),

- hemoraginė kontūzija dažniausiai būna kaktos ar pakaušio skilčių poliuose ir smegenyse prie pleištakaulio sparno.

2. Kaukolès lūžimai:

- kaukolès pamato lūžimai nustatomi KT atliekant specialiu „kauliniu režimu“ 2,5 - 5 mm pjūviais, o kartais net plonesniais. Netiesioginiai kaukolès pamato lūžimo požymiai KT yra pneumocefalija ar likvoras pridètiniuose ančiuose,

- skliauto kaulų lūžimai (linijiniai, impresiniai, per siūles).

3. Kiti pakenkimai:

- smegenų išemija (mažai ryški per pirmąsias 24 val.),

- pneumocefalija,

- smegenų vidurinès linijos ir kitų struktūrų dislokacijos,

- intraskilvelinè kraujosruva pasitaiko apie 10 proc. pacientų po sunkios GST,

- hidrocefalija ir jos forma (okliuzinè, susisiekiančioji),

- smegenų edema: smegenų pamato cisternų obliteracija, skilvelių ir smegenų vagų suspaudimas,
- smegenų anoksijos požymiai: ribos tarp smegenų pilkosios ir baltosios medžiagų neryškumas, smegenų ede$\mathrm{ma}[4-6]$.

Foramen Monro lygyje išmatuojamas atstumas tarp kaukolès kaulų vidinès plokštelès ir skaidriosios pertvaros (septum pellucidum) ir apskaičiuojama smegenų vidurinės linijos (SVL) dislokacija.

Smegenų pamatinès cisternos vertinamos vidurinių smegenų lygyje išskiriant 3 dalis (kraštus): vieną užpakalinę ir dvi šonines. Kiekviena dalis vertinama atskirai, nustatant, ar ji užspausta, ar atvira. Pamatinès cisternos gali būti $[6,8,21]$ :

- atviros, jeigu atviros visos 3 dalys,

- iš dalies užspaustos, jeigu užspausta 1 arba 2 dalys,

- visiškai užspaustos, jeigu užspaustos visos 3 dalys.

Potrauminio „masès efekto“ (hematomos, kontūzinių židinių) tūris tiksliausiai apskaičiuojamas naudojant specialias KT programas (tiesioginis volumetrinis matavimas). Dažniausiai taikomas elipsoidinis „masės efekto“ tūrio matavimo KT metodas, kuris remiasi koncepcija, kad elipsoido tūris yra apytiksliai lygus 1/2 tūrio gretasienio stačiakampio, turinčio tokius pat ilgio-pločio-aukščio matmenis, kaip elipsoidas, t.y. $\mathrm{V}=\mathrm{ABC} / 2$. Pagal šią formulę intracerebrinès hematomos ar kontūzijos tūris (ml) apskaičiuojamas atliekant tokius matavimus: identifikuojamas KT pjūvis, kuriame hematomos plotas yra didžiausias, ir jame išmatuojami A ir B dydžiai, kur A - didžiausias ilgis $\mathrm{cm}, \mathrm{B}$ - didžiausias plotis cm, kuris yra statmenas A matmeniui, o $\mathrm{C}$ - nustatomas $\mathrm{KT}$ pjūvių, kuriuose tęsiasi hematoma, skaičius $[6,8,9,13]$.

Analizuojant kitus tyrimus teigiama, jog laiku atlikta GSKT padeda sutaupyti ligoninès lèšas, nes pacientui greičiau nustatoma tiksli diagnozè ir, jei nèra pavojingų pakenkimų, jis siunčiamas gydytis ambulatoriškai, pacientas apsaugomas nuo hospitalinių infekcijų [1,15]. Ankstyvas GSKT padeda ịvertinti paciento būklę ir pateikti jam tikslesnes rekomendacijas, kiek laiko reikètų ilsėtis, kad potrauminès baigtys būtų kuo palankesnès [15]. Neginčijamas faktas, kad kaukolès KT vertingas tyrimas esant GST laiko ir kokybès atžvilgiu. Galvos smegenų struktūriniams pažeidimams - reikalinga neurochirurginè pagalba, tokiems kaip epidurinès ar subdurinès hematomos. Šie pakitimai puikiai aptinkami KT vaizduose. Tačiau kiti pažeidimai, kurie gali komplikuotis sunkiu neurologiniu pakenkimu, tokie kaip difuzinis aksonų sužalojimas ar galvos smegenų kraujagyslių pažeidimai, yra dažnai nepastebimi KT vaizduose $[2-5,11,23]$. Dèl šių priežasčių dar gana sudėtinga įžvelgti GST baigtis iš pradinio GSKT vaizdo. Kai kurie tyrimai teigia, jei ryškèja simptomai ir yra įtariamas galvos smegenų pažeidimas, patartina kartoti KT kas 6 valandas pirmąą parą. 
Visi galvos smegenų traumos sužalojimai taip pat gali būti vizualizuojami naudojant magnetinio branduolių rezonanso tyrimą (MRT), tuo tarpu kartais jie gali būti nepastebimi KT vaizdų peržiūrose [15]. Tačiau MRT nèra pasiekiamas 24 val. daugumoje ligoninių ir laiko atžvilgiu esant ūminei traumai yra per ilgas tyrimas, todèl KT išlieka pirmo pasirinkimo tyrimas esat GST. Kai kuriose rekomendacijose patariama ịvykdyti MRT per pirmą savaitę po galvos smegenų traumos, kad identifikuotume papildomą intraaksialini galvos smegenų pakenkimą [3,5,11,23].

Kompiuterinès tomografijos nauda ligos eigos ir baigčių prognozavimui. Išanalizavus daugelị atliktų tyrimų, pacientų, patyrusių GST, baigtys yra skirstomos pagal Glasgow komų skalę i grupes: miręs, vegetacinès būklès, sunkus neigalumas, vidutinis neigalumas ir pasveikimas [12]. Tačiau tam didelę ịtaka daro ir GSKT. KT verte pacientams, patyrusiems GST, galima vertinti keletu aspektu. Pirmiausia šiems ligoniams yra labai svarbu tikslios diagnozės ir gydymo pradžios laikas. GST svarbu pradèti gydyti per pirmają, vadinamają , ,auksinę" valandą [4, 15]. KT tyrimas yra greitas, todèl puikiai tinka vertinant tokius pacientus, kada reikalinga greita diagnozè ir kryptinga pagal$\mathrm{ba}$, gerinanti traumos baigtis. Greitas diagnozès nustatymas padeda priimti teisingus klinikinius sprendimus, sudaryti tinkamą paciento gydymo bei stebėsenos planą, išvengti daugelio komplikacijų ir letalios baigties. Kiekviena minutė yra svarbi, nes nuo jos priklauso smegenų pažeidimo plotas, o tai lemia tolesnes ligonio baigtis. Kitas KT privalumas pacientams po galvos smegenų traumų yra didelis jautrumas masės efektui, vertinant skilvelių dydị ir konfigūraciją, kaulų sužeidimus ir ūminị kraujavimą [7, 22].

Amerikoje, Virdžinijos valstijoje, buvo atliktas tyrimas, kurio metu buvo vertinamos GST baigtys atlikus ankstyvą KT tyrimą. İ tyrimą įtraukta 160 pacientų, iš kurių 36 proc. pasveiko, 24 proc. liko liekamujų reiškinių po traumos, 8 proc. tapo neigalūs, 2 proc. pateko ị vegetacinę būklę ir 30 proc. mirè. Šis tyrimas buvo lyginamas su kitoje šios valstijos ligonineje atliktu tyrimu, kuriame ne visiems pacientams po GST buvo atlikta ankstyva KT. Paaiškejo, jog pastarojoje ligoninejje mirtingumas nuo GST žymiai didesnis, daugiau pacientų tapo neigaliais ir pateko ị vegetacinę būklę [18]. Tyrimo rezultatai rodo, jog ankstyvas KT tyrimas turi didelę reikšmę geresnèms baigtims po GST.

Tačiau KT yra santykinai nejautrus aptikti padidẻjusi kaukolès vidinį slègị arba smegenų edemą ir ankstyvuosius hipoksinès-išeminès encefalopatijos požymius, kurie gali lydèti galvos smegenų traumą. Tokie pacientai yra vertinami kaip patyrusieji lengvą galvos smegenų traumą ir pagal GKS yra 14-15 balų. Jiems KT neatliekama arba atliekama tik ankstyvuoju laikotarpiu. Ši būklè JAV dar yra vadinama „kalbantis ir miręs" - pacientas po GST sąmoningas, ben- draujantis, pirminiuose KT vaizduose nerandama jokių pakitimų, tačiau būklè staiga pradeda blogèti ir ligonis miršta. Dẻl šitų priežasčių GSKT būtina pakartoti po 72 valandų, o esant blogèjančiai būklei - kas 6 valandas. Pakartotinio KT metu galima aptikti „,ǔdelstas“ hematomas, hipoksijos ir/ ar išemijos sukeltus pažeidimus ar smegenų edemą, o tai lemia tolesnius personalo veiksmus ir dažnai išgelbejja paciento gyvybę [7,15,18,22]. Pagal Naujojo Orleano strategiją KT būtina atlikti visiems pacientams, patyrusiems GST, kurių GKS yra vertinama 14 balų ir mažiau [7].

\section{Išvados}

Ankstyvas įvertinimas su apskaičiuotu tomografinio vaizdo gavimu (KT) yra standartinis tyrimas asmenims, patyrusiems sunkias galvos smegenų traumas, o asmenims, patyrusiems lengvą galvos smegenų traumą, KT atliekama remiantis GKS rezultatais. Ankstyvas KT atlikimas turi didelę reikšmę tolesniam klinikiniam ịvertinimui, smegenų edemos laipsnio nustatymui ir aptinkant neurochirurginius pažeidimus, tokius kaip intrakranijines, ekstrakranijines hematomas. Trauminis subarachnoidinis kraujavimas ir intrakranijinių pažeidimų buvimas asocijuojasi su nepalankiomis pacientui baigtimis $[2,5,23]$. KT rezultatai pranašauja mirties ir funkcinės padèties galimybes po galvos smegenų traumų [15]. Greitas būklès įvertinimas leidžia pasirinkti adekvačius gydymo ir ligonio monitoravimo būdus ir pasiekti geresnių rezultatų gydant ligoni, patyrusi galvos smegenu traumą ir vertinant jo tolimesnes baigtis bei esant LGST palengvinti sprendimą dèl paciento hospitalizavimo būtinumo. Dẻl šios priežasties beveik visi pacientai, patyrę reikšmingą galvos smegenų traumą, yra ịvertinami atliekant kompiuterinę tomografiją kuo anksčiau po sužalojimo.

\section{Literatūra}

1. Borg J, Holm L, Peloso PM, Cassidy JD, Carroll LJ, von Holst H, Paniak C, Yates D. Non-surgical intervention and cost for mild traumatic brain injury: Results of the WHO Collaborating Centre Task Force on Mild Traumatic Brain Injury. Journal of Rehabilitation Medicine. 2004; 43(Supplement 1): 76-83.

2. Coral L, Herrero JI, Monfort JL, Ventura JL, Javierre CF, Juncadella M, Ahueta LG, Bartolome C, Gabarros A. First CT findings and improvement in GOS and GOSE scores 6 and 12 months after severe traumatic brain injury. Brain injury. 2009; 23(5): 403-410.

3. Cole JP. Imaging after brain injury. British journal of anaesthesia. 2007; 99 (1): 49-60.

4. Davis PC. Head trauma. American journal of neuroradiology ( AJNR).2007; 28: 1619-1621.

5. Firsching R, Woischneck D, Klein S, Ludwig K, Dohring W. Brain - stem lesions after head injury. Journal of clinical pathology. 1970; 4: 154-165. 
6. Gentry LR, Godersky JC, Thompson B, Dunn VD. Prospective comparative study of intermediate-field MR and CT in the evaluation of closed head trauma. American Journal of Roentgenology. 1988; 150: 673-682.

7. Hessmann MH, Hofmann A, Kreitner KF, Lott C, Rommens PM. The benefit of multislice CT in the emergency room management of polytraumatized patients. Acta chirurgica belgium. 2006; 106: 500-507.

8. Hofmana PAM, Staperta SZ, Kroonenburgha MJPZ, Jollesa J, Kruijka J, Wilminka JT. MR Imaging, Single-photon Emission CT, and Neurocognitive Performance after Mild Traumatic Brain Injury. American journal of neuroradiology ( AJNR). 2001 22: 441-449.

9. Howard M. Eisenberg MD, Howard E. Gary Jr, Aldrich FE, Saydjari CA, Turner B, Foulkes MA, Jane J, Marmarou A, Lawrence A, Marshall F, Young HF. Initial CT findings in 753 patients with severe head injury, A report from the NIH Traumatic Coma Data Bank. Journal of Neurosurgery. 1990; 73(5): 688-98.

10. Ichise M, Chung DG, Wang P, Wortzman G, Gray BG, Frank W. Technetium-99m-HMPAO SPECT in the evaluation of patients with a remote history of traumatic brain injury: a comparison with x-ray computed tomography. Journal of Nuclear Medicine : Official Publication, Society of Nuclear Medicine. 1992; 33(1): 52-8.

11. Jennett B, Bond M. Assessment of outcome after severe brain damage. Lancet. 1975; 1(7905): 480-484.

12. Lerner EB, Moscati RM. The golden hour: scientific fact or medical "urban legend"? Acad Emerg Med. 2001; 8: 758-760.

13. Marshall LF, Marshall SB, Klauber M, Clark MB. A new classification of head injury based on computerized tomography. Journal of neurosurgery. 1991; 75 (Suppl): 14-20.

14. Perel PA. Predicting outcome after traumatic brain injury: practical prognostic models based on large cohort of international patients. MRC CRASH Trial Collaborators. British Medical Journal (BMJ). 2008; 336: 425.

15. Sadowski-Cron C, Schneider J.R.G, Senn P, Radanov B.P, Ballinari P, Zimmermann H. Patients with mild traumatic brain injury: Immediate and long-term outcome compared to intra-cranial injuries on CT scan. Brain injury. 2006; 20(11): 1131-1137. Available at: http://informahealthcare.com/doi/ abs/10.1080/02699050600832569.

16. Sherer M, Stouter J, Hart T, Nakase-Richardson R, Oliver J, Manning E, Yablon SA. Computed tomography findings and early cognitive outcome after traumatic brain injury. USA. Brain Injury. 2006; 20(10):997-1005. Available at: http://informahealthcare.com/doi/full/10.1080/02699050600677055.

17. Smits M, Hunink M, Rijssel DA, Dekker HM, Vos PE, Kool DR, Nederkoorn PJ, Hofman M, Twijnstra A, Tanghe HLJ, Dippel D.W. Outcome after Complicated Minor Head Injury. American journal of neuroradiology ( AJNR). March 2008 29: 506-513.

18. Stein SC, Fabbri A, Servadei F, Glick HA. A Critical Comparison of Clinical Decision Instruments for Computed To- mographic Scanning in Mild Closed Traumatic Brain Injury in Adolescents and Adults. Annals of Emergency Medicine. 2009; 53(2): 180-188.

19. Thurman D, Guerrero J. Trends in hospitalization associated with traumatic brain injury. The Journal of the American Medical Association (JAMA). 1999;282(10):954-957.

20. Vos PE, Alekseenko Y, Battistin L, Ehler E, Gerstenbrand, Muresanu DF, Potapov A, Stepan CA, Traubner P, Vecsei L, Wild K. Mild Traumatic Brain Injury. European Journal of Neurology. 2012; 19: 191-8.

21. Wani A, Ramzan A, Raina T, Malik NK, Nizami FA, Qayoom A, Singh G. Skull base fractures: An institutional experience with review of literature. The Indian Journal of Neurotrauma. Online publication date: 2013 . Available at: http://www.ijntonline.net/article/S0973-0508(13)00040-3/fulltext.

22. Ward JD, Greenberg RP, Young HF, Sakalas R. The outcome from severe head injury with early diagnosis and intensive management. Journal of Neurosurgery. 1977; 47(4): 491-502.

23. Wiesmann M, Steinmeier E, Magerkurth O, Linn J, Gottmann $\mathrm{D}$, Missler U. Outcome prediction in traumatic brain injury: comparison of neurological status, CT findings, and blood levels of S100B and GFAP. Acta Neurologica Scandinavica. 2010; 121: 178-185.

\section{COMPUTED TOMOGRAPHY TACTICS AND IMPORTANCE ON BRAIN INJURY EVALUATION AND PROGNOSIS}

A. Vilkė, K. Pundinaitė, E. Keleras, A. Basevičius, S. Lukoševičius, D. Bilskienè, A. Macas

Key words: computed tomography, CT performance tactics, brain injury, CT value after brain injury.

Summary

This article provides an overview of the literature on brain injuries, their outcomes and head computed tomography influence on monitoring brain injuries and treatment results. Traumatic brain injury (TBI) is an relevant medical and social problem throughout the world. It is one of the most common reasons for disability in Lithuania. TBI is defined as a condition which it characterized as the impact of the kinetic energy to the skull and the brain, causing functional and morphological changes in the brain and disrupting their activity. Currently the initial assessment in patients after traumatic brain injury is based on clinical studies (Glasgow coma scale (GCS)) and brain computed tomography. Immediate therapeutic decisions are based on the mentioned studies. However, mild traumatic brain injuries are experienced the most, the symptoms of which can be seen only with the help of computed tomography, GCS does not indicate the current injury. We decided to review the foreign literature data on the brain computed tomography and its value on the assessment of traumatic brain injuries for this reason.

Correspondence to: vilkealina@gmail.com

Gauta 2014-04-02 